\title{
Accurate, TATA box-dependent polymerase III transcription from promoters of the c-myc gene in injected
Xenopus oocytes
}

\author{
David L. Bentley, ${ }^{1,3}$ William L. Brown, ${ }^{1}$ and Mark Groudine ${ }^{2}$ \\ ${ }^{1}$ Molecular Genetics of Differentiation Laboratory, ICRF Laboratory, London, WC2A 3PX, UK; ${ }^{2}$ Division of Basic Sciences, \\ Fred Hutchinson Cancer Research Center, Seattle, Washington 98104 USA and Department of Radiation Oncology, \\ University of Washington, Seattle, Washington 98195 USA
}

\begin{abstract}
We have investigated the factors that permit a gene normally transcribed by RNA polymerase II to be transcribed by RNA polymerase III. It was shown previously that the human c-myc gene could be transcribed in vitro and in Xenopus oocytes by both $\alpha$-amanitin-sensitive and $\alpha$-amanitin-resistant polymerases, probably corresponding to polymerase II and polymerase III. We confirmed this observation in microinjected oocytes and showed that the $\alpha$-amanitin-resistant transcription of $c$-myc was competed by known polymerase III genes. Polymerase III transcription of c-myc was very inefficient compared to other polymerase III genes, however, and was observed only when large amounts of template DNA were injected. At lower DNA concentrations the gene was transcribed, exclusively by polymerase II. In contrast, the adenovirus major late promoter was not transcribed by polymerase III. The 5' ends of polymerase III RNAs were almost indistinguishable from those of polymerase II RNAs initiating at the P1 and P2 promoters of the human and mouse c-myc genes. Furthermore, point mutations in the TATA box of the human P2 promoter greatly reduced polymerase III activity. At this promoter, therefore, polymerase II and polymerase III recognize a common element, the TATA box, which probably plays an important role in specifying the start site of transcription for both polymerases. We suggest that the highly accurate though inefficient mimicry of polymerase II by polymerase III at the c-myc promoters reflects the common evolutionary origin of these two enzymes.
\end{abstract}

[Key Words: RNA polymerase II; RNA polymerase III; TATA box; c-myc; Xenopus oocyte]

Received March 22, 1989; revised version accepted May 26, 1989.

In recent years it has become clear that the promoters of genes transcribed by RNA polymerases II and III have a number of features in common (for review, see Folk 1988; Sollner-Webb 1988). Perhaps this is not surprising in view of the fact that these enzymes share a number of identical or homologous subunits (Buhler et al. 1987). A striking example of the relationship between polymerase II and polymerase III promoters is that a common transcription factor, OTFl, activates the polymerase III promoter for U6 small nuclear RNA (snRNA) (Bark et al. 1987; Carbon et al. 1987), as well as a number of polymerase II promoters such as histone H2B and U2 snRNA (Mattaj et al. 1985; Sive and Roeder 1985). In addition, like many polymerase II genes, some polymerase III genes have TATA-like sequences $20-30$ bases $5^{\prime}$ of the start site, which influence transcriptional efficiency (Larson et al. 1983, Morton and Sprague 1984; Garcia et al. 1987; Murphy et al. 1987; Mattaj et al. 1988).

${ }^{3}$ Corresponding author.
Perhaps the most impressive example of the convergence of polymerase II and polymerase III promoters was found in the human $\mathrm{c}-m y c$ gene. Transcription of this gene in vitro and in Xenopus oocytes was found to have $\alpha$-amanitin-sensitive and -resistant components consistent with transcription by both polymerases (Chung et al. 1987). In this paper we report that c-myc is transcribed by polymerase III at DNA concentrations far above those at which polymerase II transcritpion from the same promoters has saturated. Also, we show that the sites of initiation by polymerase II and polymerase III in the c-myc gene are virtually identical. The coincidence of $5^{\prime}$ ends implies that common promoter elements may be involved in both modes of transcription. This prediction was confirmed by mutagenesis experiments that identified the TATA box as critical for both polymerase II and polymerase III function. We suggest a model in which similar or possibly identical TATAbinding factors can interact with both polymerases but much more weakly with polymerase III than polymerase 
II. This model accounts for the absence of polymerase III c-myc transcription in mammalian cells and its extreme DNA concentration dependence in injected oocytes.

\section{Results \\ DNA concentration dependence of polymerase III transcription}

We and others have observed that when the human or mouse c-myc genes were injected into Xenopus oocytes, they were transcribed accurately and exclusively by polymerase II (Nishikura 1986; Bentley and Groudine 1988). Paradoxically, it also has been reported that the human c-myc gene could be transcribed in oocytes in the presence of $\alpha$-amanitin, producing RNAs that terminated at runs of $U$ residues. Presumably, these RNAs were synthesized by polymerase III (Chung et al. 1987). The results in Figure 1 show that the discrepancy between these studies is explained by the differing amounts of DNA injected. Various amounts of the plasmid pGC1HR containing the human c-myc gene on a 8.1-kb HindIII-EcoRI fragment were injected into oocytes in the presence or absence of $1 \mu \mathrm{g} / \mathrm{ml} \alpha$-amanitin, which inhibits polymerase II selectively. c-myc transcripts were assayed by RNase protection using a probe that detects $3^{\prime}$ ends in the region of the exon 1 /intron 1 boundary. When a small amount of DNA was injected (1.75 ng per oocyte), transcription was entirely $\alpha$-amanitin-sensitive, whereas when larger amounts were used, a significant amount of $\alpha$-amanitin-resistant transcription occurred. The presumed polymerase III transcripts all terminated at site I (Fig. 1), which corresponds to a run of $7 \mathrm{U}$ residues, 20 bases from the $3^{\prime}$ end of exon 1. Site I was identified previously as one of the two major positions of premature termination by polymerase II (Bentley and Groudine 1988). Thus, polymerase III and polymerase II terminate transcription at the same U-rich sequence. However, deletion analysis has shown that the run of $U$ residues is not, in fact, essential for polymerase II termination at this position (Bentley and Groudine 1988). The level of polymerase II transcription of c-myc did not increase at DNA levels $>1.75 \mathrm{ng}$ (Fig. 1). Hence, polymerase II activity was saturated at DNA levels $<1.75 \mathrm{ng}$ per oocyte. There was no evidence for polymerase III competing with polymerase II at high DNA concentrations; polymerase III transcripts accumulated in addition to, not at the expense of, polymerase II transcripts.

We also tested whether the mouse c-myc gene was transcribed by polymerase III in oocytes. The results in Figure 2 show a nuclease S1 protection assay of transcripts made after injection of a plasmid containing the entire mouse gene on a 19.8 -kb partial BamHI-EcoRI fragment (pRB 16.8; Adams et al. 1985). Just as for the human gene, transcription was entirely due to polymerase II at low amounts of injected DNA, whereas significant $\alpha$-amanitin-resistant transcription occurred when a large amount of template was injected. Polymerase II activity was saturated at the lowest amount of DNA tested (0.7 ng per oocyte). A substantial fraction of

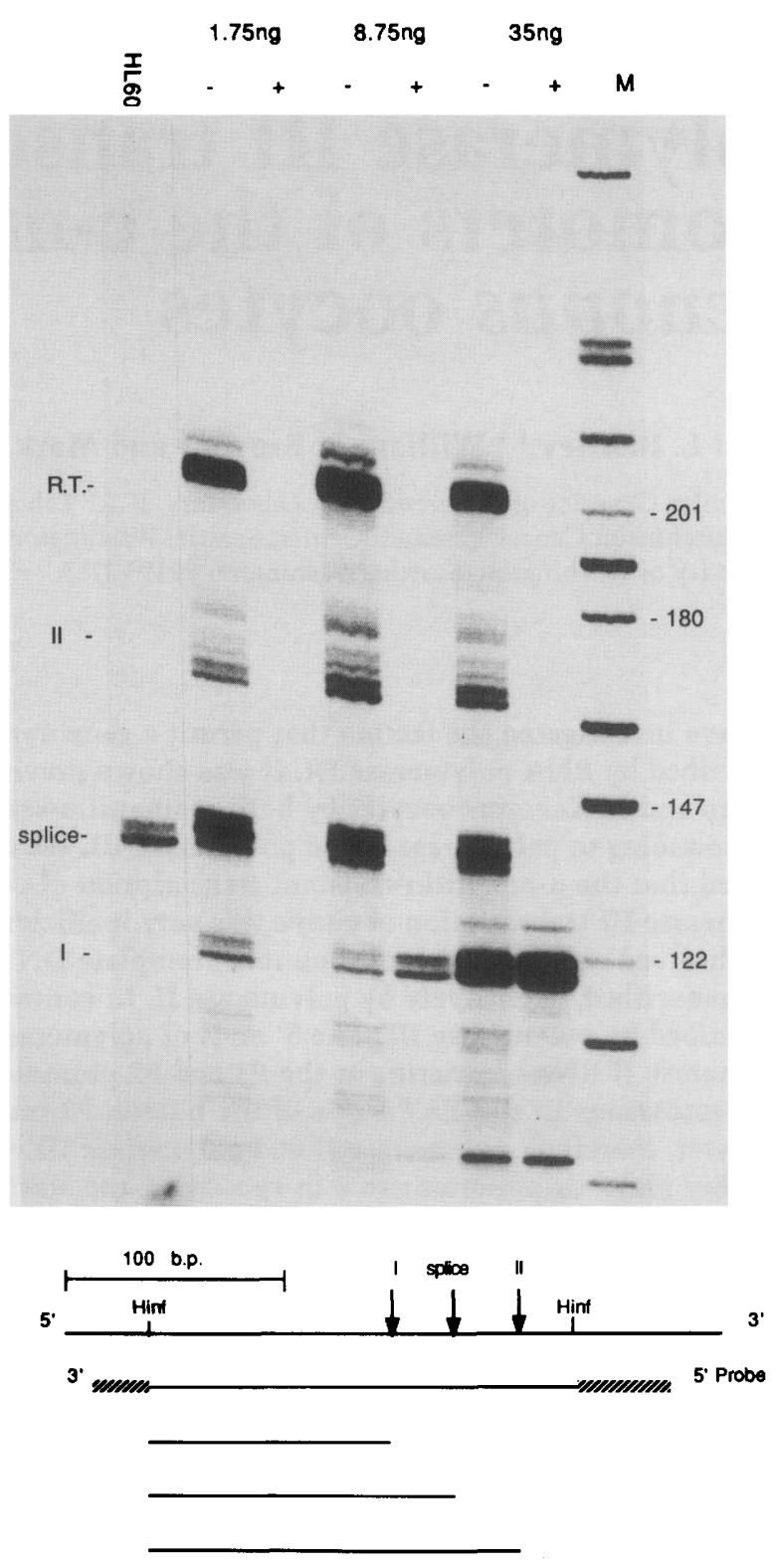

Figure 1. DNA concentration dependence of $\alpha$-amanitin-resistant transcription of the human c-myc gene. RNase protection strategy is diagramed. (HL60) Ten micrograms of total RNA, $1.75,8.75$, or $35 \mathrm{ng}$ of pGClHR was injected per oocyte + or $\alpha$-amanitin. (M) MspI-cut pBR322; (R.T.) Read-through RNA; (splice) correctly spliced RNA; (I and II) RNAs with 3 ' ends at sites I and II (for the sequence of these sites see Bentley and Groudine 1988).

polymerase II RNAs and all of the polymerase III RNAs terminated at a T-rich sequence 290 bases downstream of the P2 initiation site (Bentley and Groudine 1988). Thus, in both the human and mouse genes, the T-rich polymerase III termination sites coincide with the positions of premature termination by polymerase II, although termination is less efficient in the latter case. In 


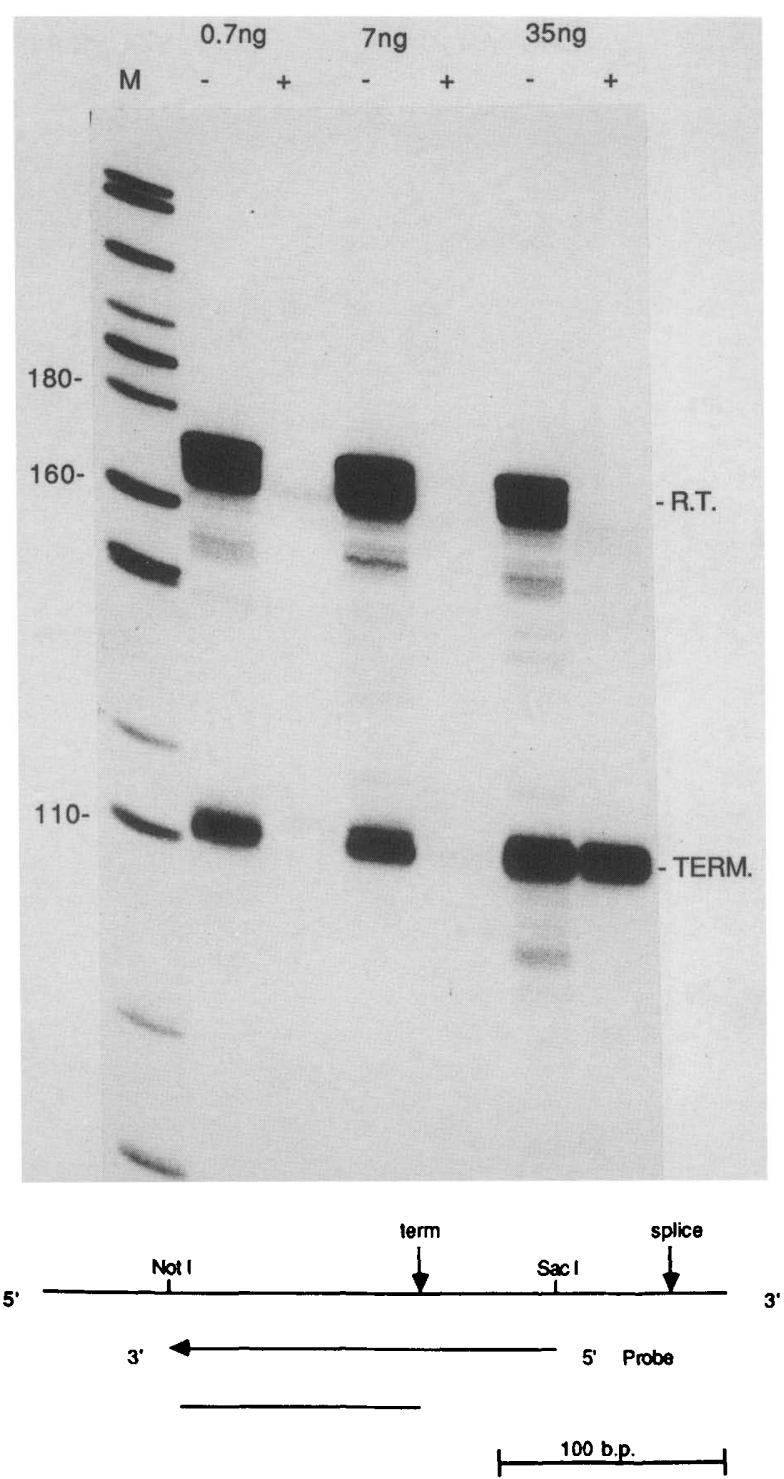

Figure 2. DNA concentration dependence of $\alpha$-amanitin-resistant transcription of the mouse c-myc gene. S1 nuclease protection was as diagramed. pRB16.8 $(0.7,7$, or $35 \mathrm{ng})$ was injected per oocyte + or $-\alpha$-amanitin. (M) MspI-cut pBR322; (R.T.) read-through RNA; (TERM) terminated RNA.

summary, the results show that transcription by an $\alpha$ amanitin-resistant polymerase, presumably polymerase III, is conserved between the human and mouse c-myc genes and that it occurs only at high concentrations of template DNA.

\section{Polymerase II and polymerase III $5^{\prime}$ ends coincide at both the $P 1$ and $P 2$ promoters}

Chung et al. (1987) demonstrated that polymerase III RNAs initiate in the region of the human P2 promoter. We attempted to determine how close the polymerase II and polymerase III initiation sites are to one another by high-resolution 5' end mapping. Polymerase II RNAs were obtained from oocytes injected with $<2$ ng DNA and polymerase III RNAs from oocytes injected with $>20 \mathrm{ng}$ in the presence of $\alpha$-amanitin. The $5^{\prime}$ ends of polymerase II and polymerase III RNAs from the mouse $\mathrm{P} 2$ promoter were indistinguishable at the resolution of the $\mathrm{S} 1$ protection experiment in Figure 3A, estimated to be \pm 5 bases. The $5^{\prime}$ ends at the human $\mathrm{P} 2$ promoter were mapped at single nucleotide resolution. Primer extension analysis (Fig. 3A, left) showed that the major initiation sites for polymerase II and polymerase III were identical. S1 analysis showed extensively overlapping but reproducibly different patterns of 5 ' ends for polymerase II and polymerase III (Fig. 3A, middle). This difference is probably due to the presence of a cap on the polymerase II RNAs, which interferes with nuclease S1 digestion.

The experiments shown in Figure 3A detected little or no $\alpha$-amanitin-resistant transcription from the P1 promoter of either the mouse or human c-myc genes. However, because the probes used in these experiments were 5 '-end-labeled downstream of $\mathrm{P} 2$, they would not have detected RNAs that terminated between P1 and P2. Runs of $\mathrm{T}$ residues likely to function as polymerase III terminators are situated just upstream of the P2 promoter in both genes. Therefore, we hybridized the same RNAs with probes that were 5 '-end-labeled at positions between P1 and P2 and upstream of the potential polymerase III terminators. The results in Figure 3B demonstrated $\alpha$-amanitin-resistant transcription from the P1 promoters of both genes. Just as for P2, polymerase III RNAs from Pl were only detected when large amounts of DNA were injected, and the 5' ends of these transcripts were indistinguishable from those of polymerase II transcripts. $\mathrm{Pl}$ is a 5- to 10 -fold weaker polymerase III promoter than $\mathrm{P} 2$ in both the mouse and human genes.

\section{Competition with polymerase III promoters}

Clearly, the c-myc gene can be transcribed by a polymerase that is $\alpha$-amanitin-resistant and terminates at runs of $U$ residues. Is this enzyme really polymerase III or a variant form of polymerase II? This question was approached by looking for competition between c-myc and either a 5S maxigene (pXbs 115/77; Bogenhagen and Brown 1981) or a U6 snRNA gene (pU6-1, Carbon et al. 1987). Both these genes are transcribed by polymerase III. However, the U6 promoter elements are upstream of the transcribed region and include a TATA box, whereas $5 \mathrm{~S}$ has an internal promoter and lacks a TATA box. The experiment was carried out by first injecting $7 \mathrm{ng}$ of either vector control or polymerase III competitor plasmid, waiting $60 \mathrm{~min}$ for transcription complexes to assemble, and then injecting $35 \mathrm{ng}$ of c-myc plasmid plus $\alpha$-amanitin. Oocyte RNA was harvested $24 \mathrm{hr}$ later and assayed for $\mathrm{c}-\mathrm{myc}$ transcripts by $\mathrm{S} 1$ protection. The result in Figure 4 (left) shows that the 5S and U6 genes both compete with c-myc relative to the vector plasmid pGEM2 (Promega). To control for the amount of c-myc plasmid injected, the samples were treated with RNase A, Southern blotted, and hybridized to an exon I probe 


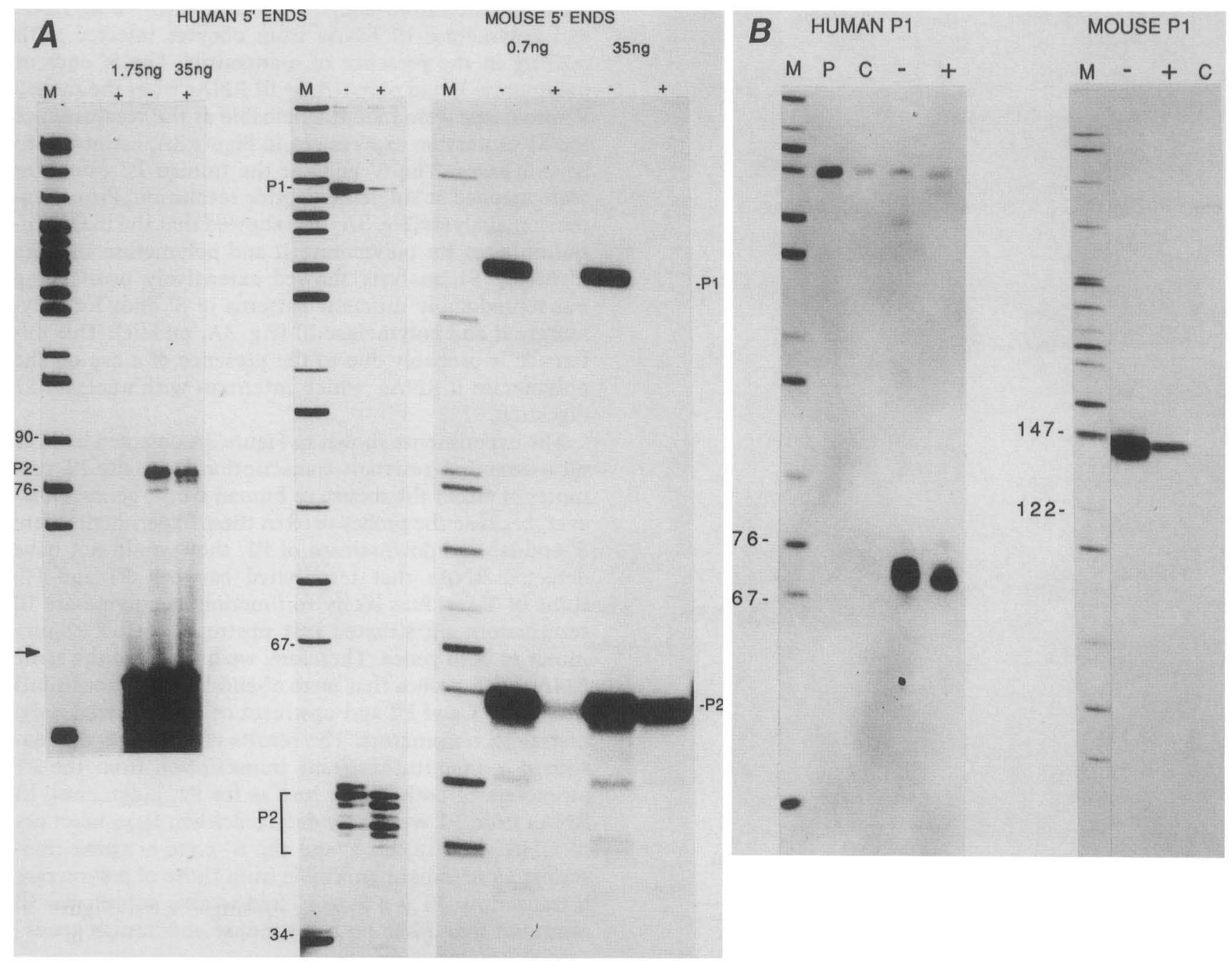

Figure 3. (A) 5 '-end mapping of transcripts from the human and mouse P2 promoters. (Left) Primer-extension mapping of the human P2 initiation site. RNAs are the same as in Fig. 1, with two oocyte equivalents of RNA per lane. The arrow indicates the oligonucleotide probe and $\mathrm{P} 2$ indicates the extension product. (Middle) S1 mapping of the human c-myc initiation sites. The RNAs analyzed were the $1.75 \mathrm{ng}-\alpha$-amanitin and the $35 \mathrm{ng}+\alpha$-amanitin samples from Fig. 1 (Right) S1 mapping of mouse c-myc initiation sites. The RNA samples analyzed were the same as those in Fig. 2. (B) S1 mapping of transcripts from the human and mouse P1 promoters. (Left) (lane $P$ ) probe, (lane $C$ ) control oocyte RNA; (lanes - and $+\mid 1.75 \mathrm{ng}-$ and $35 \mathrm{ng}+\alpha$-amanitin samples in Fig. 1. (Right) (lanes - and $+\mid 0.7 \mathrm{ng}-$ and $35 \mathrm{ng}+\alpha$-amanitin samples in Fig. 2. (C) Control oocyte RNA.

(Fig. 4, left). The results show that the U6 gene with its upstream promoter is a significantly more effective competitor than the $5 \mathrm{~S}$ gene, which has an internal promoter. This result implies that the U6 and c-myc polymerase III promoters may bind common factors not shared with the $5 \mathrm{~S}$ promoter.

\section{Specificity of the DNA concentration requirement}

The amount of polymerase III transcription does not vary linearly with the amount of c-myc plasmid DNA injected. It is undetectable below $\sim 5 \mathrm{ng}$ and rises rapidly above $\sim 10 \mathrm{ng}$ per oocyte (Figs. 1 and 2). The dramatic DNA concentration dependence could be due to a specific requirement for a high concentration of the $\mathrm{c}-\mathrm{myc}$ template. Alternatively, a high concentration of nonspecific DNA could stimulate polymerase III transcription by titrating inhibitors or affecting chromatin assembly, as observed previously for the $5 \mathrm{~S}$ and $\mathrm{U} 6$ genes (Gargiulo and Worcel 1983; D.L. Bentley, unpubl.). This question was investigated by coinjecting $1.75 \mathrm{ng}$ of a human c-myc plasmid (pGClHR) with $35 \mathrm{ng}$ of the pGEM2 vector plasmid. Under these conditions, c-myc transcription remained entirely $\alpha$-amanitin-sensitive (Fig. 4, middle). Thus, unlike other polymerase III genes tested in the injected oocyte, c-myc transcription is not activated by coinjection with nonspecific carrier DNA. It remained possible, however, that saturation of polymerase II activity was needed for activation of polymerase III at the $c-m y c$ promoters. Therefore we preinjected oocytes 
with a saturating amount ( $25 \mathrm{ng}$ ) of a plasmid containing the adenovirus major late promoter (MLP), which is transcribed actively in oocytes (Fig. 4, right): One hour later, $1.75 \mathrm{ng}$ of a c-myc plasmid was injected and tested for $\alpha$-amanitin-resistant transcription. The result (Fig. 4, middle) showed complete $\alpha$-amanitin sensitivity. The absence of polymerase III activity was not due to competition by the MLP for polymerase III factors, because this promoter does not compete with U6 transcription when coinjected in a 10 -fold molar excess (data not shown). Thus, saturating amounts of a polymerase II promoter cannot activate c-myc polymerase III transcription in trans. In contrast to c-myc, virtually all transcription from the adenovirus MLP was sensitive to $1 \mu \mathrm{g} / \mathrm{ml} \alpha$ amanitin when $35 \mathrm{ng} /$ oocyte of the pSma $\mathrm{F}$ plasmid (Weil et al. 1979) was injected (Fig. 4, right). In conclusion, polymerase III transcription of c-myc specifically requires a high concentration of the template DNA, implying that the promoter is recognized relatively inefficiently by this polymerase compared with polymerase II.

\section{$5^{\prime}$ and $3^{\prime}$ deletions of the P2 promoter}

What sequence elements of the c-myc gene are recognized by polymerase III? The A box consensus situated $\sim 40$ bases downstream of the $P 2$ start site and conserved between the mouse and human genes may be of functional importance (Chung et al. 1987). This hypothesis was tested by constructing a $3^{\prime}$ deletion of the human gene that removes the A box and retains only $\sim 30$ bases of c-myc sequence downstream of the P2 start site (for sequence, see Materials and methods). This deletion mutant (pmyc $\Delta \mathrm{A}$ box) is transcribed by polymerase III as efficiently as the wild-type gene, implying that the $\mathrm{A}$ box does not play a significant role in polymerase III transcription of the gene (Fig. 5, left). In this respect, the c-myc polymerase III transcription unit resembles the U6 snRNA and 7SK genes, whose promoters do not require transcribed sequences (Murphy et al. 1987; Das et al. 1988).

The polymerase III requirements for upstream sequences were investigated using a $5^{\prime}$ deletion of the 8.1kb HindIII-EcoRI fragment (pmyc 31), which removes a 612-bp region ending 3 bases upstream of the TATAAAA motif at P2 (Nishikura 1986). The pmyc 31 gene was not transcribed by either polymerase II or polymerase III when it was injected at $\mathbf{l} \mathrm{ng}$ per oocyte (data not shown); however, it was transcribed by polymerase III when a large amount of DNA (>20 ng) was injected (Fig. 5). Under these conditions, the pattern of $5^{\prime}$ ends detected by S1 protection was characteristic of polymerase III, both in the presence and absence of $\alpha$-amanitin (Fig. 5, lanes myc31 - and +1. For comparison, the polymerase II pattern of S1 resistant bands exemplified by mRNA from HL60 cells and wild-type c-myc RNA made in oocytes (Fig. 5, lane $\mathrm{C}$ ) is shown. As a control for $\alpha$-amanitin inhibition, a U2 snRNA maxigene (Mattaj et al. 1985) was coinjected with pmyc 31 and found to be completely sensitive (Fig. 5 , right). The efficiency of polymerase III transcription from the $5^{\prime}$ dele- tion was not significantly less than that of the complete gene. Thus, polymerase II transcription can be abolished by $5^{\prime}$ deletion without significantly affecting polymerase III function. In summary, the deletion analysis shows that all of the sequences necessary for polymerase III activity of $\mathrm{P} 2$ appear to lie within the region -35 to +30 .

\section{The TATA box is essential for polymerase III function}

The almost exact coincidence of $5^{\prime}$ ends generated by the two polymerases at the $\mathrm{P} 2$ promoter (Fig. $3 \mathrm{~A}$ ) implies that a common element might fix the initiation sites for both enzymes. An obvious candidate for such an element is the TATA box. A 7-base deletion of the sequence TATAAAA was introduced into the $8.1-\mathrm{kb}$ HindIII-EcoRI fragment containing the human c-myc gene cloned in the Bluescript vector (Stratagene). The mutant plasmid (pmyc $\triangle$ TATA) was injected into oocytes at high DNA concentration ( $35 \mathrm{ng}$ per oocyte), and 5 ' ends were mapped by an Exo VII protection assay. No transcription by either polymerase was observed from the $\mathrm{P} 2$ promoter, in contrast to abundant transcription from P1 (Fig. 6, left). The TATA box at P2 is therefore essential for both polymerase II and polymerase III function. To distinguish a requirement for an AT-rich region from a requirement for a specific sequence, a single base substitution was introduced at P2 generating the sequence TTTAAAA. For this experiment, the 860-base PvuII fragment, which includes both promoters and all but 40 bases of exon I, was inserted into M13 (clone mp11-Pvuex1) and subjected to oligonucleotide-directed mutagenesis. Polymerase III transcription was monitored from the wild-type and mutant genes in the same vector, the two DNAs differing by a single base. Figure 6 (middle) shows in vivo-labeled RNA synthesized in the presence of $\alpha$-amanitin after coinjection of $35 \mathrm{ng}$ of the c-myc gene as plus $0.7 \mathrm{ng}$ of the $5 \mathrm{~S}$ maxigene. Polymerase III terminates efficiently at a run of $4 \mathrm{U}$ residues, fortuitously situated just downstream of the polylinker in the vector so that a 380-base RNA is made following initiation at $\mathrm{P} 2$. The 185 -base RNA made from the wildtype template was very variable in its intensity relative to the 380-base RNA, and it has not been characterized further. The $5 S$ gene served as a control for the amount of DNA injected. It is clear from the experiment in Figure 6 that the TTTAAAA point mutant virtually abolishes polymerase III transcription. To control for the stability of the injected DNA, the oocyte extracts were Southern-blotted and hybridized to an exon I probe. No difference between the amounts of wild-type and mutant DNAs was detected (data not shown). In addition, a second mutation was introduced to create the sequence TTTATAA at the P2 promoter. The double mutant failed to restore polymerase III activity (Fig. 6). Therefore, it is concluded that the sequence TATAAAA functions far better than TTTAAAA or TTTATAA to promote transcription by polymerase III at the $\mathrm{P} 2$ promoter in the context of the intact c-myc gene (see Discussion).

The polymerase II activity of the point mutants was measured to determine whether the same stringent se- 
Figure 4. (Left $\rangle$ Competition between polymerase III genes and human c-myc. (GEM, U6 and 5S) Oocytes were injected with $7 \mathrm{ng}$ of pGEM2, pU6-1, or pXbs $115 / 77$, respectively, and challenged $60 \mathrm{~min}$ later with $35 \mathrm{ng}$ of pGC1HR plus $\alpha$-amanitin. S1 analysis of RNA is shown in the first panel. Southern blot of injected pGClHR c-myc plasmid in the oocyte extracts hybrized to an exon 1 probe. (Middle) Effect of coinjected plasmids on c-myc transcription. (GEM - and +) A mix of $1.75 \mathrm{ng}$ of pGC1HR and $35 \mathrm{ng}$ of pGEM2 was injected per oocyte - or $+\alpha$-amanitin. (SmaF - and $+\lcm{25} \mathrm{ng}$ of pvZ-SmaF was injected per oocyte and 60 min later $1.75 \mathrm{ng}$ of pGClHR + or $-\alpha$-amanitin. (Right) $\alpha$-Amanitin sensitivity of adenovirus MLP transcription. RNase protection of samples injected with 35 ng per oocyte of pSmaF - or $+\alpha$-amanitin.

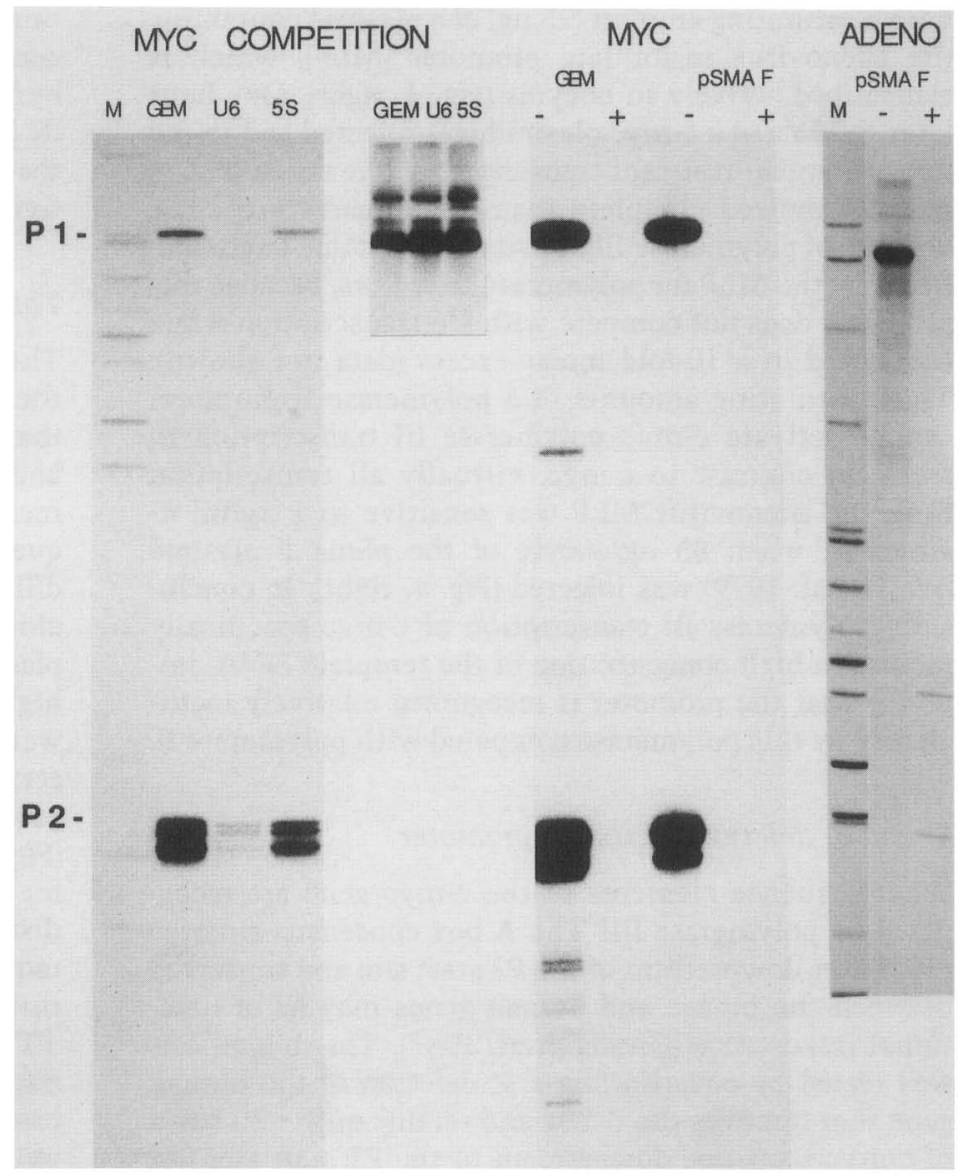

DNA levels ( $>20$ ng per oocyte), an $\alpha$-amanitin-resistant polymerase is active also. The latter behaves like polymerase III by two criteria, in addition to its resistance to low concentrations of $\alpha$-amanitin, namely termination at runs of $U$ residues and competition with $U 6$ and $5 S$ genes. The $\mathrm{A}$ box consensus, 40 bases downstream of the P2 promoter, is dispensable for polymerase III transcription just as it is in the U6 and 7SK genes (Murphy et al. 1987; Das et al. 1988). It has been suggested that U6 may be transcribed by a variant form of polymerase III or a hybrid of polymerase II and polymerase III subunits (Das et al. 1988; Fold 1988), and we cannot exclude such a possibility for c-myc. However for the sake of discussion, we refer to the $\alpha$-amanitin-resistant enzyme transcribing c-myc as polymerase III.

The $5^{\prime}$ ends of c-myc polymerase III RNAs were almost indistinguishable from those of polymerase II RNAs assayed by high-resolution S1 and primer extension mapping (Fig. 3). This result indicated that common promoter elements may interact with both polymerases to specify the initiation site. Strong support for this hypothesis came from the observation that a 7-base deletion of the sequence TATAAAA in the human P2 promoter abolished polymerase III and polymerase II function (Fig. 6). The TATA box therefore is essential for both modes of transcription. A TATA box-like sequence is also an important component of the polymerase III 


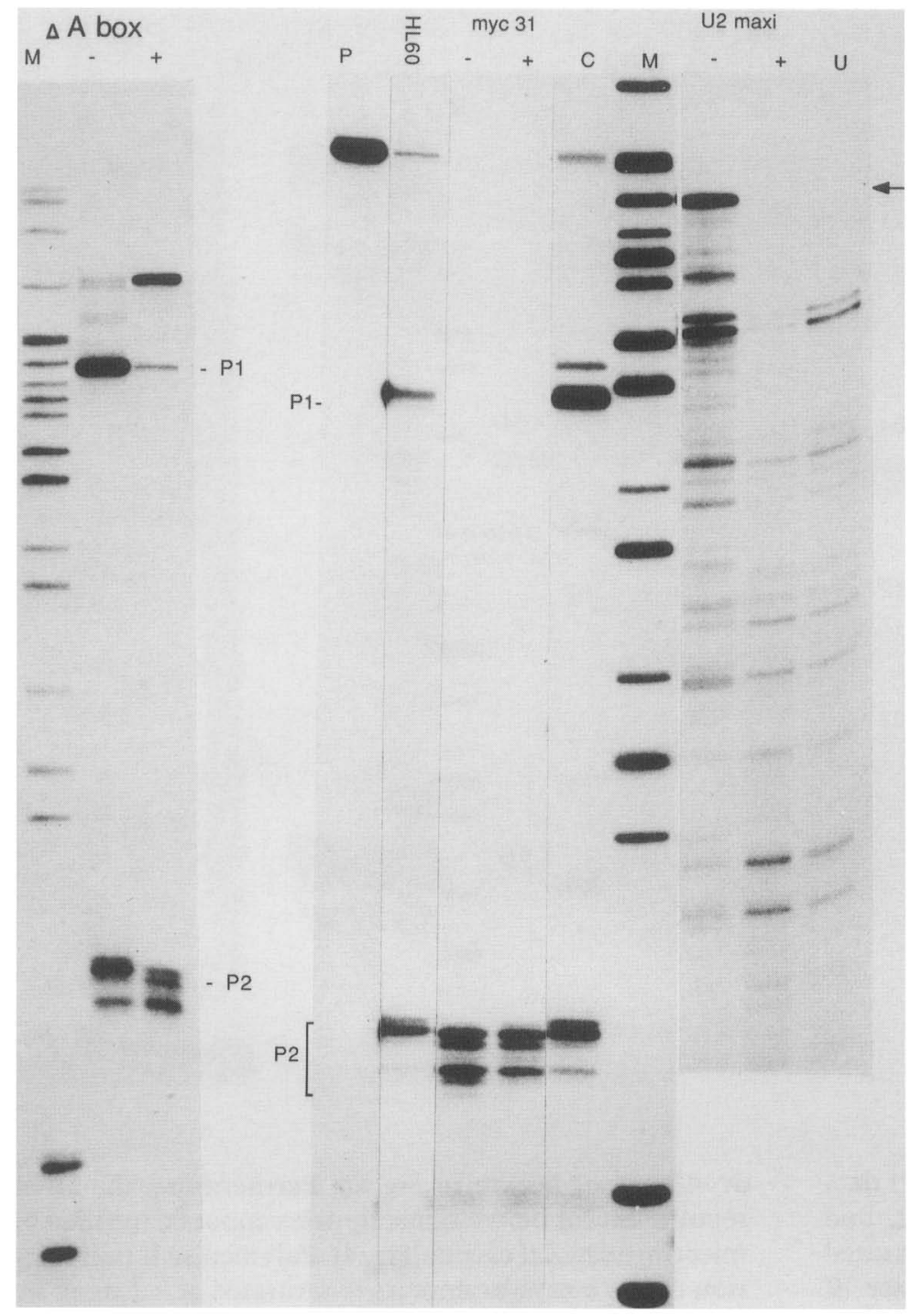

Figure 5. Polymerase III transcription of $5^{\prime}$ and $3^{\prime}$ deletions of the human c-myc gene. (Left) S1 mapping 5' ends of RNAs from the 3' deletion plasmid, pmyc $\Delta \mathrm{A}$ box. Plasmid was injected at $35 \mathrm{ng}$ per oocyte - or $+\alpha$-amanitin. The 300 -base band is undigested probe (Middle) S1 mapping $5^{\prime}$ ends of RNAs from the $5^{\prime}$ deletion pmyc 31. (P) Probe; (HL60) 10 $\mu \mathrm{g}$ total RNA; (myc 31 - and +) $35 \mathrm{ng}$ of injected plasmid per oocyte, either - or + $\alpha$-amanitin, (C) Wild-type c-myc plasmid pGCIHR at $1.75 \mathrm{ng}$ per oocyte. (Right) RNase protection of transcripts from the $\mathrm{U} 2$ maxigene coinjected with pmyc 31 at $0.7 \mathrm{ng}$ per oocyte, - and + correspond to the same RNA samples analyzed in middle. (U) Uninjected oocyte RNA. The arrow indicates the injected U2 maxigene, and the remaining bands correspond to endogenous U2 transcripts. promoter of the 7SK gene. Introduction of $3 \mathrm{GC}$ bp into the 7SK TATA box abolished transcription in vitro (Murphy et al. 1987). We measured the polymerase II and polymerase III activity of single and double AT substitutions in the TATAAAA sequence of the human P2 promoter. When introduced into the intact $c-m y c$ gene, the mutants TTTAAAA and TTTATAA are impaired severely in polymerase III activity but relatively unaffected in polymerase II activity. Interestingly, the TTTAAAA point mutant did not have such a dramatic inhibitory effect when it was introduced into a myc gene with a $5^{\prime}$ deletion (pmyc 31) that removes sequences up to 3 bases away from the TATA box (D.L. Bentley, unpubl.). It is possible that removal of the P1 promoter is responsible for this effect, either because it competes with P2 for TATA-binding factors or because readthrough transcription from $\mathrm{Pl}$ disrupts complexes at P2 (Henderson et al. 1989). In analogous experiments on the Xenopus tropicalis U6 gene, mutation from CTTATAA to TTTAAAA had little effect on polymerase III tran- scription (Carbon et al. 1987). However, deletion of the TATA box abolished transcription when tested in competition with a wild-type U6 promoter (Mattaj et al. 1988).

Our experiments do not allow us to distinguish whether distinct or identical TATA box-binding factors interact with polymerase II and polymerase III at the c-myc promoters. We observed that a c-myc gene transcribed exclusively by polymerase III (pmyc 31 ) competes effectively with the adenovirus MLP when it is coinjected in a 20 -fold molar excess (data not shown). This effect could result from competition for a common factor. Alternatively, the large excess of injected c-myc plasmid that is not transcribed actively could bind different polymerase II- and polymerase III-specific TATA factors. Davison and colleagues (1983) demonstrated that small restriction fragments not able to support transcription can still compete for TATA factors.

It is not known why some polymerase II promoters are recognized by polymerase III and others are not, but the 
Figure 6. TATA box mutations disrupt polymerase III transcription of the human c-myc gene. (Left) Exo VII mapping the $5^{\prime}$ ends of RNAs from wildtype (pGClHR) and TATA box deletion (pmyc $\Delta$ TATA) plasmids injected at $35 \mathrm{ng}$ per oocyte $+/-$ $\alpha$-amanitin. (Middle) In vivo GTP ${ }^{32}$ P-labeled polymerase III RNAs from oocytes injected with wildtype, TATAA, or two point mutants, TTTAA and TTTAT, at $35 \mathrm{ng}$ per oocyte plus $\alpha$-amanitin along with $0.7 \mathrm{ng}$ of pXbs $115 / 77$ SS plasmid. (Right) S1 mapping 5 ' ends of polymerase II transcripts from the wild-type and point mutants injected at $1.4 \mathrm{ng}$ per oocyte. A shorter exposure of the Pl-specific band is shown at bottom.

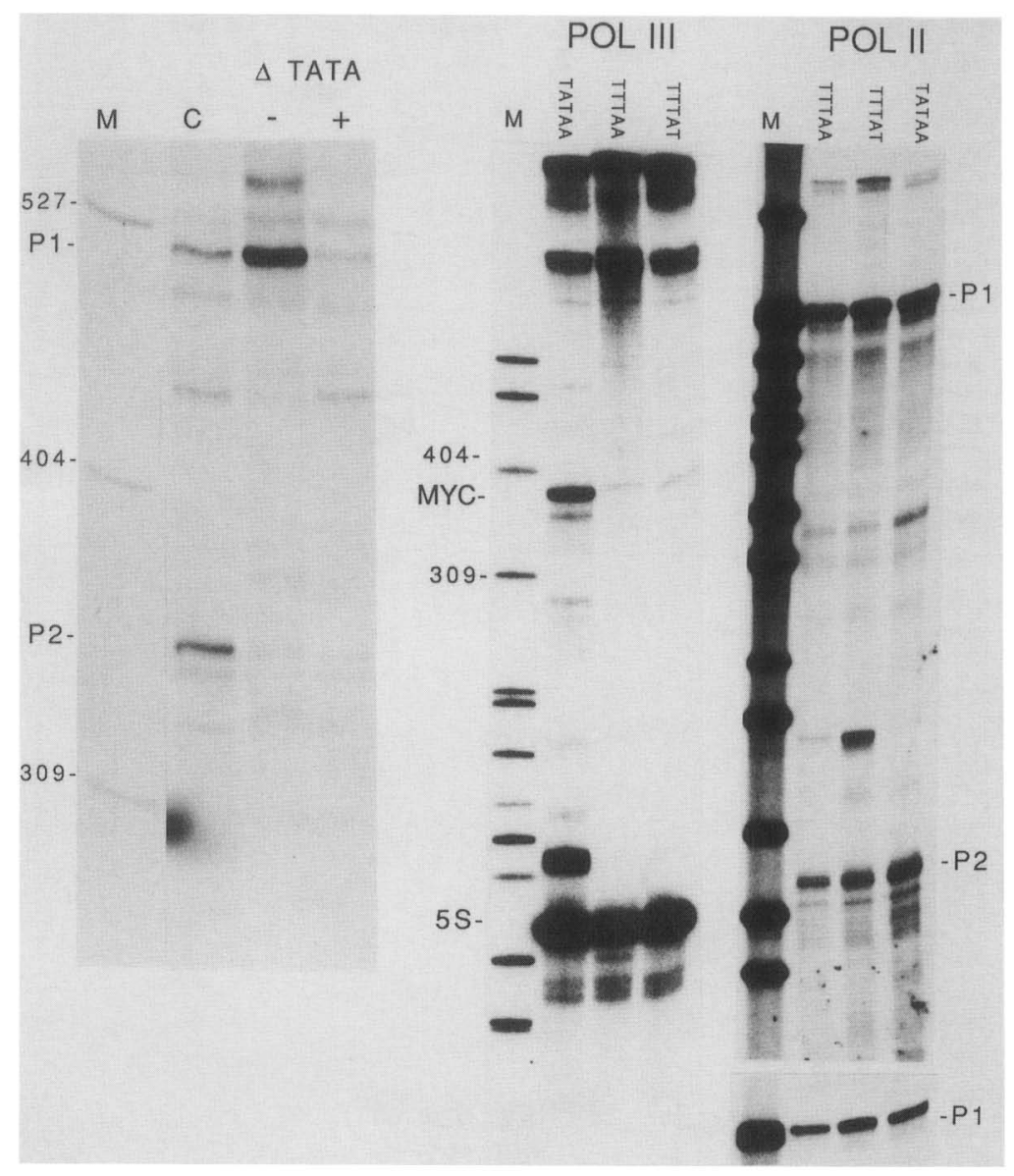

TATA box sequence clearly has an influence. $\mathrm{Pl}$ is a much weaker polymerase III promoter than $\mathrm{P} 2$, and when the P1 TATA sequence TTTATAA, is substituted for the normal P2 sequence, it inhibits polymerase III activity severely without affecting polymerase II greatly (Fig. 6). Although the sequence of the TATA box can have a dramatic effect, it is not the only determinant of polymerase III transcription, because identical TATA sequences occur at the c-myc $\mathrm{P} 2$ promoter and the adenovirus MLP, which is not recognized by polymerase III to a significant degree (Fig. 4). Possibly the sequence of the initiation site influences polymerase III activity, as Mattaj and colleagues (1988) have shown recently for the U6 snRNA gene. These workers also demonstrated a low level of polymerase II transcription from this polymerase III promoter. Unlike the c-myc promoter, the polymerase II activity was TATA box independent and appeared to resemble transcription of other snRNAs such as $U 1$ and $U 2$. Although we do not fully understand the determinants of low-level polymerase III transcription at polymerase II promoters, this phenomenon might provide a novel way of distinguishing different classes of polymerase II promoter.

The high DNA concentration required for polymerase III transcription of c-myc is in sharp contrast to other polymerase III promoters that function efficiently at low levels of injected template (e.g., see the $5 S$ gene injected at $<1 \mathrm{ng}$ per oocyte in Fig. 6). Furthermore, the DNA requirment for $c-m y c$ transcription cannot be fulfilled by injecting plasmid carrier (Fig. 4). Polymerase II transcription of the c-myc promoters is saturated at $<1 \mathrm{ng}$ of injected DNA per oocyte (Fig. 2), whereas maximal polymerase III transcription requires at least 20 times that amount. The data in Figure 6 show that the human c-myc $\mathrm{P} 2$ promoter is transcribed by polymerase III several hundred times less efficiently per template molecule than a coinjected $5 \mathrm{~S}$ gene. The c-myc promoters clearly are recognized inefficiently by polymerase III compared with polymerase II. This conclusion is consistent with transcriptional runoff experiments in isolated nuclei (Bentley and Groudine 1986), demonstrating that the $c-m y c$ gene is not naturally transcribed by polymerase III to a detectable extent. We confirmed recently these results in HL60 cells using two different protocols (Miller et al. 1978; Jackson and Cook 1985) in which runoff transcription occurs in whole cells permeabilized under isotonic conditions (C. Spencer, M. Groudine, and D.L. Bentley, unpubl.). Therefore, the importance of polymerase III transcription of $c-m y c$ in vivo remains equivocal.

Recognition of polymerase II promoters by polymerase III can be interpreted as an evolutionary vestige of the common origin of the two polymerases, which allows polymerase III to respond to the TATA-box, albeit at a 
low efficiency. Our data are consistent with the idea that TATA-binding factors direct initiation by both polymerases at the same site in the human c-myc gene but that transcription complexes containing polymerase II assemble much more readily than those containing polymerase III.

\section{Materials and methods}

\section{Oocyte injection}

Oocytes were injected with $70 \mathrm{nl}$ of DNA solution in $10 \mathrm{~mm}$ Tris- $\mathrm{HCl}(\mathrm{pH} 7.5)$ and $0.1 \mathrm{mM}$ EDTA. $\alpha$-Amanitin was injected cytoplasmically to a final concentration of $1 \mu \mathrm{g} / \mathrm{ml}$. Nucleic acids were extracted from pools of 10-20 healthy oocytes by homogenizing in $0.25 \mathrm{ml}$ of $1 \%$ SDS, $0.1 \mathrm{M}$ Tris $\langle\mathrm{pH} 8.0\rangle$, and 10 $\mathrm{mM}$ EDTA, then adding $0.25 \mathrm{ml}$ of $4 \mathrm{M}$ guanidinium isothiocyanate, $5 \mathrm{~mm}$ sodium citrate $(\mathrm{pH} 7.0), 0.1 \mathrm{M} \beta$-mercaptoethanol, and $0.5 \%$ sarkosyl, and extracting once with phenol/chloroform $(1: 1)$ and once with chloroform followed by ethanol precipitation.

\section{RNase, S1, and ExoVII mapping}

Hybridizations and nuclease digestions were as described previosly (Bentley and Groudine 1988). Unless stated otherwise, one oocyte equivalent $(\approx 5 \mu \mathrm{g}$ ) of RNA was used per gel lane. Restriction sites in the $c-m y c$ genes used in preparation of the probes are shown in the maps, along with the termination sites I, II, and T and the splice sites. Marker lanes (M) in all figures contain MspI digested pBR322.

Probes Figure 1: SP6 RNA was made from pGEM-Hinfwt template. Figure 2: The 165-base NotI-SacI fragment from exon I of the mouse c-myc gene was $3^{\prime}$-labeled by filling in the NotI site with Klenow fragment. Figure 3A: For primer extension, the oligonucleotide 5'-AGCTCTGCTCGCCCGGCTCTTC-3', complementary to the sequence $60-80$ bases downstream of $\mathrm{P} 2$, was end-labeled with polynucleotide kinase. The human S1 protection probe was the 300-base SmaI-NaeI fragment spanning the $5^{\prime}$ end of exon 1, 5'-end-labeled at the NaeI site. The mouse probe was the 540 -base ScaI-NotI fragment spanning the $5^{\prime}$ end of exon 1, 5'-end-labeled at the NotI site. Figure 3B: The human probe contained the 170-base SmaI-Xhol fragment spanning Pl plus $\sim 10$ bases of polylinker. It was 5 -end-labeled at the $X$ hoI site. The mouse probe was the 360-base RsaI-HindIII fragment spanning the Pl promoter $5^{\prime}$ end-labeled at the HindIII site. Figure 4: S1 protection of c-myc RNA was with a 350 -base single-stranded 5 '-end-labeled probe extending from the oligonucleotide primer used in Figure $3 \mathrm{~A}$ to the Smal site, 100 bases upstream of Pl. It was synthesized by priming on single-stranded mpll-Puv exl. The adenovirus probe was an 800-base $\mathrm{T} 7$ transcript made from $\mathrm{pVZ}-\mathrm{SmaF}$, linearized with XhoI, 260 bases upstream of the MLP start site.

Figure 5: The $\Delta$ A box probe was a 310 -base $S m a I-A s p 718$ fragment, 5 '-end-labeled at the Asp 718 site in the polylinker just downstream of the deletion endpoint in the plasmid pmyc $\Delta \mathrm{A}$ box. The probe used in Figure 5 (middle) was a 240-base fragment that includes the 140-base XhoI-NaeI fragment of the c-myc gene spanning P2, as well as 100 bases of irrelevant sequence. It was $5^{\prime}$-end-labeled at the NaeI site. The $\mathrm{U} 2$ maxigene probe was a 630-base SP6 transcript made from pXELU2GEM3 linearized with SmaI, 130 bases upstream of the start site.

Figure 6: The ExoVII protection probe used in Figure 6 (left) was a uniformly labeled single-stranded 860 -base PvuII fragment that includes most of exon 1. It was synthesized on the
mp11-Pvu-exl template. The S1 probe used in Figure 6 (right) was the same as that in Figure 4, except it was labeled uniformly.

\section{Plasmid constructs}

pMyc41HE and pGC1HR pMyc41HE (arRushdi et al. 1983) and pGC1HR ( a gift of E. Laufer) contain the $8.1-\mathrm{kb}$ HindIIIEcoRI fragment of the human c-myc gene in pBR322 and the pUC-based vector pGCl (Myers et al. 1985), respectively. Identical results were obtained with both plasmids.

PmycDTATA The 8.1-kb HindIII-EcoRI fragment was cloned in Bluescribe (Stratagene), and single-stranded DNA was mutated by the method of Nakamaye and Eckstein (1986) to delete the 7 base TATAAAA at the P2 promoter as confirmed by sequencing.

pmyc $\Delta A$ box The parent plasmid (pBSKS $+\mathrm{H} 3-\mathrm{Nae}$, a gift of E. Laufer) contained the 2.5-kb HindIII-NaeI fragment spanning the $5^{\prime}$ end of human c-myc cloned in Bluescript KS + (Stratagene) with a BamHI linker at the NaeI site. The plasmid was linearized with $\mathrm{BamHI}$ and digested for $2 \mathrm{~min}$ with an excess of ExoIII at $12^{\circ} \mathrm{C}$, followed by $\mathrm{Sl}$ digestion, repair with Klenow, and recircularization. The wild-type (top line) and mutant sequences starting at the approximate $\mathrm{P} 2$ initiation site are

ACTCGCTGTA GTAATTCCAG CGAGAGGCAG

ACTCGCTGTA GTAATTCCAG CGAGAGGCAG

AGGGAGCGAG CGGGCGGCCG GCTAGGGTGG

c c t c gagggg gggcccggta c c a g c t t t

The $\mathrm{A}$ box in the wild-type sequence is underlined.
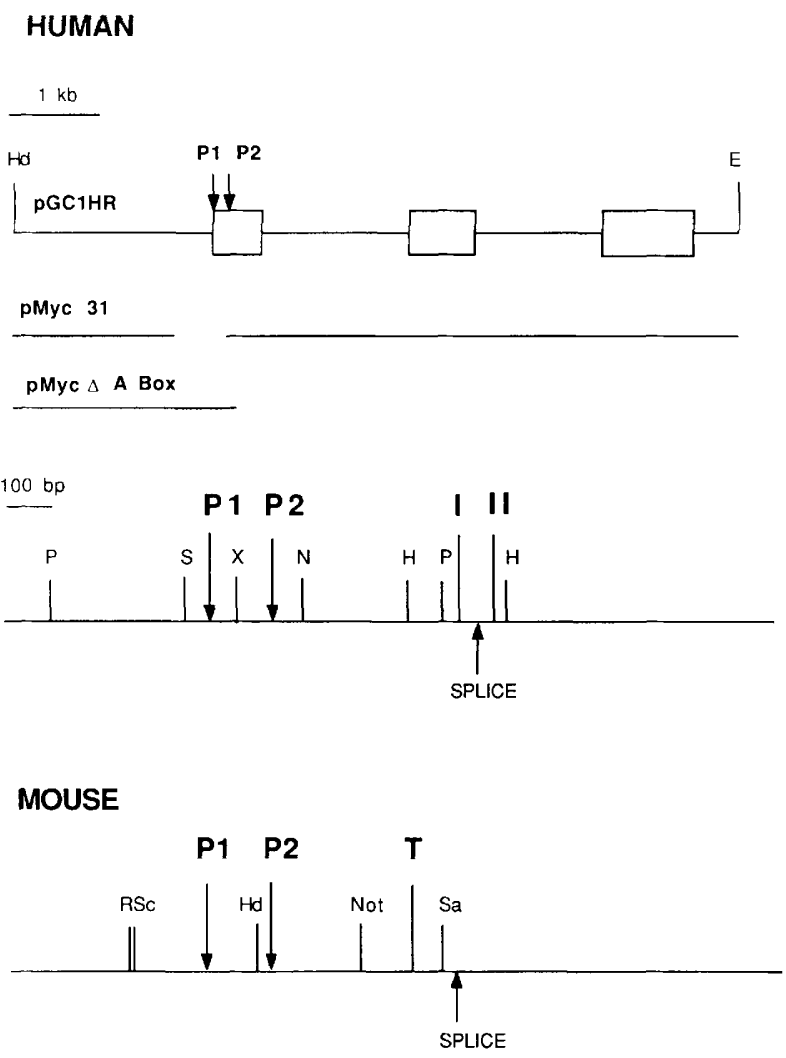

(E) EcoRl; (H) Hinfl; (Hd) Hindlli; (N) Nael; (P) Pvull; (R) Rsal; (S) Smal; (Sa) Sacl; (Sc) Scal; (X) Xhol $\mathrm{I}$, II, and $\mathrm{T}$ : termination sites 
PGEM-Hinfwt The 190-bp HinfI fragment spanning the end of human c-myc exon 1 was cloned with BamHI linkers into pGEM3.

mp11-Pvu-ex1 This plasmid contains the 860-base Pvull fragment of human c-myc exon 1 cloned in M13 mpl1. Oligonucleotide-directed point mutants TTTAAAA and TTTATAA at P2 were confirmed by DNA sequencing.

pmyc 31 This plasmid (full designation pMyc31XmaI3), obtained from $\mathrm{K}$. Nishikura, contains the $8.1-\mathrm{kb} H$ indIII-EcoRI human c-myc fragment cloned in pML. The region between bases 1846 and 2458 has been deleted and replaced by an XbaI linker. The deletion endpoint is the same as II5'-33 in Nishikura (1986).

$p R B$ 16.8 This plasmid contains a 16.8 -kb EcoRI partial BamHI fragment of the mouse c-myc gene in pUC9 (Adams et al. 1985).

pXELU2-GEM3 This subclone of the Xenopus laevis U2 maxigene (Mattaj et al. 1985) in pGEM3 was a gift of J. Izant.

$p V Z-S m a F$ The $2.5-\mathrm{kb}$ SmaF fragment of adenovirus 2 was inserted into the SmaI site of pVZ-1 (Henikoff and Eghtedarzadeh 1987).

pXbs $115 / 77$ This plasmid is the Xenopus borealis 5S maxigene (Bogenhagen and Brown 1981).

pU6-1 This plasmid is the $X$. tropicalis U6 snRNA gene (Carbon et al. 1987).

\section{Acknowledgments}

We thank M. Peretz for expert technical assistance and R. Raymond and D. Watling for supplying oocytes. E. Laufer, J. Izant, K. Nishikura, and I. Mattaj generously supplied plasmids. We are also grateful to N. Jones, E. Laufer, $\mathrm{H}$. Sive, C. Spencer, and A. Lassar for helpful discussions and comments on the manuscript. M.G. was supported by National Science Foundation grant DCB8502591 and NIH grant AI27291.

\section{References}

Adams, J., A. Harris, C. Pinkert, L. Corcoran, W. Alexander, S. Cory, R. Palmiter, and R. Brinster. 1985. The c-myc oncogene driven by immunoglobulin enhancers induces lymphoid malignancy in transgenic mice. Nature 318: 533-538.

ar-Rushdi, A., K. Nishikura, J. Erickson, R. Watt, G. Rovera, and C. Croce. 1983. Differential expression of the translocated and untranslocated c-myc oncogene in Burkitt lymphoma. Science 222: 390-393.

Bark, C., P. Weller, J. Zabielski, L. Janson, and U. Pettersson. 1987. A distant enhancer element is required for polymerase III transcription of a U6 RNA gene. Nature 328: 356-359.

Bentley, D. and M. Groudine. 1986. A block to elongation is largely responsible for decreased transcription of $\mathrm{c}-\mathrm{myc}$ in differentiated HL 60 cells. Nature 321: 702-706.

- 1988. Sequence requirements for premature termination of transcription in the human c-myc gene. Cell 53: $245-256$.

Bogenhagen, D. and D. Brown. 1981. Nucleotide sequences in Xenopus 5S DNA required for transcription termination. Cell 24: $261-270$.

Buhler, J.-M., M. Riva, C. Mann, P. Thuriaux, S. Memet, J.Y. Micouin, I. Treich, S. Mariotte, and A. Sentenac. 1987. Eukaryotic RNA polymerases and the regulation of transcription (ed. W.S. Reznikoff et al.), pp. 25-36, Elsevier, Amsterdam.
Carbon, P., S. Murgo, J.-P. Ebel, A. Krol, G. Tebb, and I. Mattaj. 1987. A common octamer motif binding protein is involved in the transcription of U6 snRNA by RNA polyerase III and U2 snRNA by RNA polymerase II. Cell 51:71-79.

Chung, J., D. Sussman, R. Zeller, and P. Leder. 1987. The c-myc gene encodes superimposed RNA polymerase II and III promoters. Cell 51: 1001-1008.

Das, G., D. Henning, D. Wright, and R. Reddy. 1988. Upstream regulatory elements are necessary and sufficient for transcription of a U6 RNA gene by RNA polymerase III. EMBO J. 7: $503-512$.

Davison, B., J.-M. Egly, E. Mulvihill, and P. Chambon. 1983. Formation of stable preinitiation complexes between eukaryotic class B trancription factors and promoter sequences. Nature 301:680-686.

Folk, W. 1988. Changing directions in polymerase III transcription. Genes Dev. 2: 373-375.

Garcia, A., A. O'Connell, and S. Sharp. 1987. Formation of an active transcription complex in the Drosophila melanogaster 5S RNA gene is dependent on an upstream region. Mol. Cell. Biol. 7: 2046-2051.

Gargiulo, G. and A. Worcel. 1983. Analysis of the chromatin assembled in germinal vesicles of Xenopus oocytes. I. Mol. Biol. 170: 699-722.

Henderson, S., K. Ryan, and B. Sollner-Webb. 1989. The promoter-proximal rDNA termination augments initiation by preventing disruption of the stable transcription complex caused by polymerase read-in. Genes Dev 3: 212-223.

Henikoff, S. and M. Eghtedarzadeh. 1987. Conserved arrangement of nested genes at the Drosophila Gart locus. Genetics 117: $711-725$.

Jackson, D.A. and P.R. Cook. 1985. A general method for preparing chromatin containing intact DNA. EMBO I. 4: 913918.

Larson, D., J. Bradford-Wilcok, L. Young, and K. Sprague. 1983. A short 5' flanking region containing conserved sequences is required for silkworm alanine tRNA gene activity. Proc. Natl. Acad. Sci. 80: 3416-3420.

Mattaj, I., S. Lienhard, J. Jiricny, and E. De Robertis. 1985. An enhancer-like sequence within the Xenopus U2 gene promoter facilitates the formation of stable transcription complexes. Nature 316: 163-167.

Mattaj, I., N. Dathan, H. Parry, P. Carbon, and A. Krol. 1988. Changing the RNA polymerase specificity of U snRNA gene promoters. Cell 55: 435-442.

Miller, M., J. Castellot, and A. Pardee. 1978. A permeable animal cell preparation for studying macromolecular synthesis. DNA synthesis and the role of deoxyribonucleotides in S phase initiation. Biochemistry 17: 1073-1080.

Morton, D.G. and K.U. Sprague. 1984. In vitro transcription of a silkowrm 5S RNA gene requires an upstream signal. Proc. Natl. Acad. Sci. 8: 5519-5522.

Murphy, S., C. Di Liegro, and M. Melli. 1987. The in vitro transcription of the 7SK RNA gene by RNA polymerase III is dependent only on the presence of an upstream promoter. Cell 51: 81-87.

Myers, R., L. Lerman, and T. Maniatis. 1985. A general method for saturation mutagenesis of cloned DNA fragments. Science 229: 242-247.

Nakamaye, K. and F. Eckstein. 1986. Inhibition of restriction endonuclease $\mathrm{NciI}$ by phosphorothioate groups and its application to oligonucleotide-directed mutagenesis. Nucleic Acids Res. 14: 9679-9688.

Nishikura, K. 1986. Sequences involved in accurate and efficient transcription of the human c-myc gene microinjected into frog oocytes. Mol. Cell. Biol. 6: 4093-4098. 
Sive, H. and R. Roeder. 1986. Interaction of a common factor with conserved promoter and enhancer sequences in histone H2B, immunoglobulin and U2 small nuclear RNA (snRNA) genes. Proc. Natl. Acad. Sci. 83: 6382-6386.

Sollner-Webb, B. 1988. Surprises in polymerase III transcription. Cell 52: 153-154.

Weil, P., D. Luse, J. Segall, and R. Roeder. 1979. Selective and accurate initiation of transcription at the $\mathrm{Ad} 2$ major late promoter in a soluble system dependent on purified RNA polymerase II and DNA. Cell 18: 469-484. 


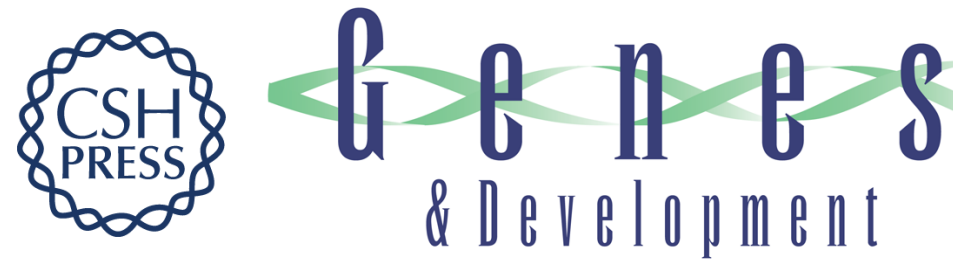

\section{Accurate, TATA box-dependent polymerase III transcription from promoters of the c-myc gene in injected Xenopus oocytes.}

D L Bentley, W L Brown and M Groudine

Genes Dev. 1989, 3:

Access the most recent version at doi:10.1101/gad.3.8.1179

References This article cites 28 articles, 9 of which can be accessed free at:

http://genesdev.cshlp.org/content/3/8/1179.full.html\#ref-list-1

License

Email Alerting

Service

Receive free email alerts when new articles cite this article - sign up in the box at the top right corner of the article or click here.

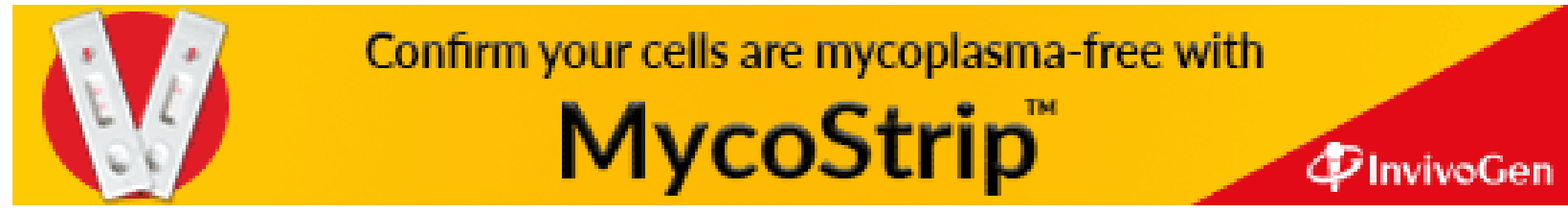

